\title{
Small female citation advantages for US journal articles in medicine ${ }^{1}$
}

Female underrepresentation continues in senior roles within academic medicine, potentially influenced by a perception that female research has less citation impact. This article provides systematic evidence of (a) female participation rates from the perspective of published journal articles in 46 Scopus medical subject categories 1996-2018 and (b) gender differences in citation rates 1996-2014. The results show female proportion increases 1996-2018 in all fields and a female majority of first authored articles in two fifths of categories, but substantial differences between fields: A paper is 7.3 times more likely to have a female first author in Obstetrics and Gynecology than in Orthopedics and Sports Medicine. Only three fields had a female last author majority by 2018, a probable side effect of ongoing problems with appointing female leaders. Female first-authored research tended to be more cited than male first-authored research in most fields (59\%), although with a maximum difference of only $5.1 \%$ (log-transformed normalised citations). In contrast, male last-authored research tends to be more cited than female last-authored research, perhaps due to cases where a senior male has attracted substantial funding for a project. These differences increase if team sizes are not accounted for in the calculations. Since female first-authored research is cited slightly more than male first-authored research, properly analysed bibliometric data considering career gaps should not disadvantage female candidates for senior roles.

Keywords: Gender differences; research evaluation; academic medicine; citation analysis

\section{Introduction}

Gender, race and social background inequalities in US medicine are being addressed at many stages of medical careers, from careful selection of applicants ${ }^{1}$ to mentoring ${ }^{2}$ and examination of salary differentials. ${ }^{3}$ Here we focus on gender disparities. Whilst females have achieved parity in medical school matriculants ${ }^{4}$ and at least parity at junior academic ranks in some specialisms, ${ }^{5}$ they remain scarce in senior roles. ${ }^{5,6,7,8}$

One possible underlying cause of the lack of females in senior posts might be a perception that their work is inferior. Females have been claimed to be less successful in some areas of medicine, by winning fewer prizes ${ }^{9,10}$ and generating fewer citations to their work ${ }^{11}$. As explained below, direct comparisons of career citations or $\mathrm{h}$-indexes between academics in Google Scholar or bibliometric lists favour males and may have helped to create an erroneous (see below) impression that males tend to outperform females in academic medicine, biasing senior promotion committees towards males.

A second issue is that if female-authored publications tend to be less cited, then a lack of citations could affect females when citation counts or the h-index are considered in promotion decisions and for funding. ${ }^{12}$ Whilst females seem to accumulate fewer career citations (as sometimes partly assessed by the h-index), ${ }^{13,14}$ raw career statistics are unfair because females are more likely to lose publishing time due to career breaks and part-time working for carer responsibilities. Studies incorporating career factors and/or academic rank have found no gender difference in productivity or h-indexes. ${ }^{5,7,15,16,17}$ Thus, if male and female candidates for a senior role started at the same time then the female candidate may have a shorter $\mathrm{CV}$, fewer career citations and a lower h-index if she took full time or part-time career breaks for carer responsibilities. A promotion committee considering all three and ignoring

\footnotetext{
${ }^{1}$ Thelwall, M. \& Maflahi, N. (in press). Small female citation advantages for US journal articles in medicine. Journal of Information Science.
} 
contributory career factors might therefore erroneously find triple evidence of greater achievement over the same period by the male candidate.

In this article we assess evidence of a gender difference in citation impact from a different perspective: the citation rate of individual articles. This has the advantage of increased robustness because it is impossible to fully disentangle career factors and changes for a large enough sample of academics to generate fair comparisons between males and females for career citations, the h-index or productivity. Whilst there have been article-level bibliometric studies of gender for individual journals, ${ }^{18,19}$ for small sets of journals or articles in a field, ${ }^{14,20,21}$ and science-wide investigations ${ }^{22}$, or selected medical fields ${ }^{23}$, large-scale country-specific studies of medicine are needed to give systematic evidence. Thus, we report a medicine-wide field-by-field analysis of changes in the proportion of US female authorship 1996-2018 and gender differences in citation rates per article 1996-2014 to test whether female-authored publications are indeed less cited.

\section{Methods}

\section{Sample}

We extracted journal article records from all 49 Scopus narrow fields within the broad category Medicine, retaining only those that are registered as standard journal articles. We excluded two categories for being too general (Medicine (all) and Medicine (miscellaneous)) and one for having only 19 qualifying articles (Reviews and References (medical)). We chose Scopus rather than the Web of Science to get a larger collection of articles. ${ }^{24}$ Medline seems to be more inclusive than Scopus, but its inclusion of apparently lower quality research would degrade the quality of the field normalisation used.

Articles were only retained when all author affiliations were in the United States, as registered in Scopus. We excluded articles with any non-US author to avoid complicating the results by the influence of international collaboration, which tends to increase citation counts. This is a substantial limitation because much important medical research is internationally collaborative, and the extent to which international research is important may vary by field. If the gender profile of the first authors of international research is different from that of national research, then the focus on national research would disadvantage the more international gender because international research tends to be more cited.

We downloaded Scopus records for 1996-2017 in November-December 2018 and records from 2018 at the end of January 2019 to ensure near-complete coverage. We used data from 1996-2018 to show authorship trends and data from 1996-2014 for citation analysis, giving each article the required minimum of three years to attract citations. ${ }^{25}$

\section{Gender detection}

We detected author genders from their names using a list of first names derived from the US census 2010 and social media profiles via genderapi.com. Only names that are at least $90 \%$ of the same gender were used to ensure a high degree of accuracy. This algorithm made 1.5 errors per 100 gender assignments on a sample of 1000 US authors manually classified for gender from a previous paper, ${ }^{26}$ but overestimated the proportion of female authors by $1 \%$. We excluded records for which the first or last author gender could not be determined, when relevant. A total of 94001 articles had a male or female first author from the US, with $76 \%$ of first author genders being detected. The missing authors had a mixture of initials rather than names, unisex names, and rare gendered names.

The gender detection method biases the results away from researchers that have emigrated to the USA or that are from ethnic minorities within the USA, since their first name 
genders are less likely to be detected from the US-based name list. This will be particularly the case for countries, such as China, where first names are often gender-ambiguous when written in the Latin alphabet. Assuming that such researchers have a different gender breakdown and seniority breakdown to the remaining scholars, the results may not be applicable to this group.

\section{Normalised citation impact}

We did not use raw citation counts directly to assess citation impact because it is not fair to compare citation counts for older articles with citation counts for newer articles because of the differing periods to accrue citations. It is also not fair to compare citation counts for articles in different fields because they attract citations at different rates due to differing typical reference list lengths, publication speeds, and types of document cited. It is even not completely fair to compare citation counts for articles from the same field and year because there may be differing degrees of interdisciplinarity, which affects citation counts. We therefore used normalised citation counts instead of raw citation counts, considering publication year, publication field and interdisciplinarity, as follows.

We calculated the Normalised Log-transformed Citation Score (NLCS) for the field and year normalised citation impact of each article, relative to the world average. This is the natural $\log$ of the citation count plus one, divided by the average of these calculations for all articles from the same field and year, $\ln (1+c) / \overline{\ln (1+c)}$. Thus, a score higher than 1 indicates more (log-transformed) citations than average for the field and year of publication. Scopus often classifies journals into more than one category. In such cases the NLCS denominator is the average of the denominators for all fields in which the article is classified (including any non-medical categories), but the article is only counted once. This adjusts for interdisciplinarity to some extent. In practice, interdisciplinarity is difficult to quantify and so this approach is an oversimplification. ${ }^{27}$ If one gender is more likely to be the first author of journal articles that are disadvantaged by this oversimplification of interdisciplinarity, then this would influence the results.

The logarithm transformation in the above formula is necessary for the normalisation process because sets of citation counts are highly skewed and follow close to a lognormal distribution. ${ }^{28}$ This affects the denominator because the arithmetic mean is inappropriate for the untransformed skewed sets of citation counts. ${ }^{29}$ The arithmetic mean of a skewed set of numbers can be dominated by the largest numbers in the set, therefore not giving a fair estimation of central tendency.

Averaging NLCS gives the Mean Normalised Log-transformed Citation Score (MNLCS) ${ }^{30}$ which can be used to compare the average citation impact of sets of articles even if they are from different fields and years. An MNLCS above 1 again indicates citation impact above the world average for the field(s) and year(s) of the set of articles involved. NLCS can be used as the independent variable for regression even if the articles are from different fields and years because of the normalisation process.

\section{Covariates}

We used first and last author gender and team size as the key independent variables. Whilst all authors contribute to an article, the first author normally performs most tasks and the most important tasks, although the last author may oversee the study. ${ }^{31}$ The gender of the first author is therefore the main independent variable, and the last author gender is a secondary independent variable. We also added the publication year as a set of independent variables (as a series of binary variables, one for each year after 1996) since the average impact of a nation's research evolves non-linearly over time. If US national impact did not vary over time, then publication years would not be needed because the expected citation impact for any year (other 
factors being equal) would be the same. Since it does vary over time (decreasing) and the proportion of female first-authored articles also varies over time (increasing), failing to account for publication year would result in a spurious attribution of a male citation advantage due to a higher proportion of male first authors in (earlier) years with a higher national citation advantage.

Since team size associates with citation rate, ${ }^{32}$ we added the number of authors as another set of independent variables for a follow-up analysis. The exact nature of the relationship is unknown so we used five team sizes $(1,2,3,4,5+)$, without using a formula for their value.

A nonparametric Wilcoxon rank sum test with continuity correction was used to check whether the number of authors associated with first author gender.

\section{Statistical analysis}

We used linear regression to assess the relationship between normalised citations (NLCS), and team size $\left(A_{i}=1\right.$ if the paper has $i=2,3,4$ authors or $A_{5}=1$ if the paper has 5 or more authors), gender ( $F=1$ if the first author is female, $L=1$ if the last author is female) and the (dummy) publication year $\left(P_{y}=1\right.$ if the paper was published in year $y$ ).

$$
N L C S=\alpha+\beta_{1} F+\beta_{2} A_{2}+\beta_{3} A_{3}+\beta_{4} A_{4}+\beta_{5} A_{5+}+\beta_{6} L+\beta_{7} P_{97}+\cdots+\beta_{24} P_{14}
$$

A secondary regression was performed without the author number independent nominal variables $A_{i}$. This regression models the first author as controlling who contributes so that the size of the team is their achievement rather than an independent input.

We used weighted least squares regression ${ }^{33,34}$ rather than ordinary least squares regression to fit the linear model due to heteroscedasticity in the publication year and gender variables.

\section{Results}

\section{Proportions of female first authors}

We wanted to know which Scopus medical categories had a majority of female first and/or last (normally senior) authors for journal articles in 2018, and how this had changed since 1996. About two fifths of the medical fields investigated (19 out of 46, or $41 \%$; $37 \%$ allowing for the $1 \%$ overestimation of females by the gender detection algorithm) had a majority of female first authors of US-only research by 2018, compared to only one field in 1996 (Table 1).

Only three fields had achieved a female last author majority by 2018 , reflecting the almost medicine-wide domination of senior roles by males. All fields had experienced an increase in the share of female first and last authors between 1996 and 2018.

Differences between fields are substantial. In 2018, the ratio of female to male first authors was 7.3 times greater in Obstetrics and Gynecology (2.4:1) than in Orthopedics and Sports Medicine (0.32:1). 
Table 1. Gender identification and share statistics for 46 Scopus narrow Medicine fields 1996-2018 (descending order of Female first in 2018).

\begin{tabular}{|c|c|c|c|c|c|c|c|c|}
\hline Narrow field & $\begin{array}{r}\text { Articles } \\
\text { with US } \\
\text { only } \\
\text { authors }\end{array}$ & $\begin{array}{c}\text { Gendered } \\
\text { first \& last } \\
\text { authors \% }\end{array}$ & $\begin{array}{r}\text { Female } \\
\text { first in } \\
1996 \%\end{array}$ & $\begin{array}{r}\text { Female } \\
\text { first in } \\
2018 \%\end{array}$ & $\begin{array}{r}\text { Change } \\
1996- \\
2018 \%\end{array}$ & $\begin{array}{r}\text { Female } \\
\text { last in } \\
1996 \%\end{array}$ & $\begin{array}{r}\text { Female } \\
\text { last in } \\
2018 \%\end{array}$ & $\begin{array}{r}\text { Change } \\
1996- \\
2018 \%\end{array}$ \\
\hline Obstetrics and Gynecology & 49997 & 63.0 & 30.4 & 70.3 & 39.9 & 27.4 & 54.9 & 27.5 \\
\hline Reproductive Medicine & 14190 & 59.5 & 28.9 & 67.1 & 38.2 & 20.9 & 45.3 & 24.5 \\
\hline Epidemiology & 38417 & 66.1 & 37.5 & 61.6 & 24.1 & 27.4 & 46.2 & 18.9 \\
\hline $\begin{array}{l}\text { Public Health, Environmental \& } \\
\text { Occupational Health }\end{array}$ & 139180 & 70.4 & 37.3 & 60.5 & 23.2 & 34.5 & 50.6 & 16.1 \\
\hline $\begin{array}{l}\text { Pediatrics, Perinatology \& Child } \\
\text { Health }\end{array}$ & 101727 & 69.2 & 39.1 & 60.4 & 21.3 & 32.9 & 46.1 & 13.3 \\
\hline Geriatrics and Gerontology & 29027 & 70.9 & 50.1 & 59.7 & 9.7 & 47.6 & 48.4 & 0.9 \\
\hline Embryology & 3987 & 58.7 & 39.7 & 59.0 & 19.3 & 16.4 & 49.5 & 33.1 \\
\hline Psychiatry and Mental Health & 128674 & 74.1 & 37.5 & 58.3 & 20.8 & 34.5 & 46.7 & 12.3 \\
\hline Genetics (clinical) & 32603 & 54.3 & 42.7 & 57.0 & 14.3 & 27.1 & 41.3 & 14.1 \\
\hline $\begin{array}{l}\text { Endocrinology, Diabetes \& } \\
\text { Metabolism }\end{array}$ & 49933 & 57.4 & 38.5 & 56.4 & 17.9 & 22.9 & 40.7 & 17.9 \\
\hline Rehabilitation & 30301 & 71.9 & 39.5 & 56.4 & 16.9 & 36.4 & 43.7 & 7.3 \\
\hline Rheumatology & 10872 & 56.4 & 34.8 & 55.3 & 20.5 & 23.8 & 44.3 & 20.6 \\
\hline Dermatology & 30827 & 65.8 & 30.7 & 53.0 & 22.3 & 23.1 & 42.2 & 19.2 \\
\hline Health Policy & 47975 & 73.6 & 30.4 & 52.7 & 22.3 & 32.6 & 44.6 & 12.1 \\
\hline Biochemistry (medical) & 9350 & 58.3 & 39.5 & 52.2 & 12.7 & 23.3 & 35.1 & 11.9 \\
\hline $\begin{array}{l}\text { Complementary \& Alternative } \\
\text { Medicine }\end{array}$ & 8234 & 67.4 & 25.4 & 51.5 & 26.1 & 23.9 & 46.6 & 22.6 \\
\hline Infectious Diseases & 66038 & 63.3 & 31.1 & 51.0 & 19.9 & 22.7 & 37.6 & 14.9 \\
\hline Health Informatics & 12934 & 63.3 & 47.0 & 50.1 & 3.1 & 43.5 & 41.0 & -2.5 \\
\hline Drug Guides & 526 & 65.0 & 22.2 & 50.0 & 27.8 & 11.1 & 50.0 & 38.9 \\
\hline Family Practice & 6474 & 77.2 & 32.6 & 49.1 & 16.5 & 36.8 & 41.6 & 4.8 \\
\hline Pathology and Forensic Medicine & 41635 & 64.1 & 30.1 & 49 & 18.9 & 22.1 & 38.8 & 16.7 \\
\hline Immunology and Allergy & 51353 & 58.3 & 33.9 & 48.8 & 14.9 & 19.2 & 32.9 & 13.7 \\
\hline Internal Medicine & 29087 & 64.1 & 30.2 & 48.8 & 18.6 & 20.9 & 37.1 & 16.2 \\
\hline Oncology & 125333 & 59.7 & 29.5 & 47.8 & 18.3 & 20.3 & 36.6 & 16.3 \\
\hline Pharmacology (medical) & 53734 & 61.0 & 28.0 & 47.5 & 19.5 & 23.0 & 36.4 & 13.4 \\
\hline Anatomy & 12068 & 63.2 & 38.7 & 47.2 & 8.6 & 26.2 & 36.7 & 10.5 \\
\hline Hematology & 42489 & 54.0 & 27.6 & 46.7 & 19.1 & 18.5 & 30.6 & 12.1 \\
\hline Microbiology (medical) & 31318 & 64.1 & 30.0 & 46.5 & 16.5 & 24.2 & 32.9 & 8.7 \\
\hline Anesthesiology \& Pain Medicine & 26321 & 64.8 & 19.7 & 43.0 & 23.3 & 19.5 & 32.2 & 12.7 \\
\hline
\end{tabular}




\begin{tabular}{|c|c|c|c|c|c|c|c|c|}
\hline Histology & 12330 & 55.5 & 41.2 & 42.9 & 1.7 & 28.3 & 36.0 & 7.7 \\
\hline Transplantation & 21795 & 50.6 & 21.5 & 42.8 & 21.4 & 13.0 & 27.5 & 14.5 \\
\hline Nephrology & 17359 & 61.5 & 26.7 & 42.6 & 15.8 & 21.4 & 25.5 & 4.2 \\
\hline $\begin{array}{l}\text { Critical Care \& Intensive Care } \\
\text { Medicine }\end{array}$ & 27379 & 68.8 & 17.1 & 39.8 & 22.8 & 13.3 & 32.0 & 18.8 \\
\hline Emergency Medicine & 28423 & 73.5 & 21.8 & 39.7 & 17.9 & 17.3 & 32.7 & 15.4 \\
\hline Ophthalmology & 49174 & 58.0 & 23.8 & 38.9 & 15.1 & 17.6 & 29.1 & 11.4 \\
\hline Physiology (medical) & 52039 & 59.7 & 21.7 & 38.3 & 16.6 & 14.6 & 27.0 & 12.4 \\
\hline Neurology (clinical) & 115803 & 63.7 & 24.1 & 37.8 & 13.7 & 17.9 & 25.7 & 7.8 \\
\hline Otorhinolaryngology & 36228 & 68.2 & 21.1 & 36.0 & 14.8 & 16.1 & 27.0 & 10.9 \\
\hline Gastroenterology & 37151 & 56.2 & 19.2 & 35.9 & 16.8 & 16.6 & 20.4 & 3.8 \\
\hline Pulmonary \& Respiratory Medicine & 43449 & 63.6 & 20.5 & 35.0 & 14.5 & 13.8 & 26.2 & 12.4 \\
\hline Urology & 34504 & 62.8 & 9.2 & 33.3 & 24.0 & 8.0 & 17.2 & 9.2 \\
\hline $\begin{array}{l}\text { Radiology, Nuclear Medicine \& } \\
\text { Imaging }\end{array}$ & 104196 & 55.8 & 21.7 & 32.9 & 11.3 & 16.5 & 23.3 & 6.8 \\
\hline Hepatology & 15405 & 56.7 & 22.2 & 32.7 & 10.4 & 14.7 & 21.3 & 6.7 \\
\hline Surgery & 163418 & 66.7 & 12.5 & 30.0 & 17.5 & 11.8 & 18.9 & 7.1 \\
\hline $\begin{array}{l}\text { Cardiology \& Cardiovascular } \\
\text { Medicine }\end{array}$ & 123747 & 63.6 & 13.6 & 28.1 & 14.5 & 10.2 & 20.2 & 10.1 \\
\hline Orthopedics and Sports Medicine & 79332 & 70.4 & 15.4 & 24.5 & 9.1 & 14.0 & 16.7 & 2.8 \\
\hline
\end{tabular}

\section{Gender differences in citations}

We also wanted to discover any gender-based citation advantages for first or last authors (our primary goal). Most fields $(57 \%, 26)$ had a female citation advantage and this advantage was statistically significant for $26 \%$ of fields (12) for females and for $17 \%$ of fields (9) for males (Table 2). The citation advantages for females were a maximum of 0.051 , equating to a $5.1 \%$ higher citation ratio for female first-authored articles than for male first-authored articles in Complementary and Alternative Medicine. For males, the statistically significant maximum was 0.057: a 5.7\% higher citation ratio in Genetics (clinical).

For last authors the position is reversed. A minority of fields $(33 \%, 15)$ had a female last author citation advantage, with differences being statistically significant for only $15 \%$ (7) whereas males had a statistically significant last author citation advantage in $37 \%$ of fields (17). The maximum statistically significant citation advantages were small for both female $(8.0 \%)$ and male $(8.0 \%)$ last authors.

Multi-author teams tend to produce statistically significantly more citations than solo author teams (Table 2, with one small field minor exception), and the team citation advantage tends to increase with the number of members (Table 2). We also found a tendency for female first authors to be in larger teams and for male last authors to be in larger teams. The team size with female first authors was larger than for male first authors in 31 out of 45 fields where there was a difference and in 10 out of 13 fields where there was a statistically significant difference (Appendix, Table A1). In contrast, the team size with female last authors was larger than for male last authors in 12 out of 45 fields where there was a difference and in 1 out of 13 fields where there was a statistically significant difference (Appendix, Table A1). 
Removing team size independent variables from the regression equations corresponds to crediting the first and/or last author with putting together the research team, rather than independently crediting the team with performing the research. Removing team size variables, there is a female first author citation advantage in $80 \%$ of fields (37 out of 46) and a male last author citation advantage in $85 \%$ of fields (39 out of 46) (Appendix, Table A2, Model 2). This strengthens the female first author and male last author citation advantage trends found when team sizes are included in the regression (and therefore factored out of the citation advantage calculations). Ignoring the first or last author gender as well makes little difference (Appendix, Table A2, Model 3 and 4).

Table 2. Regression coefficients for the full regression model for each of 46 Scopus narrow Medicine fields (US only, first and last author gendered). Publication year regression coefficients are not shown. Order as in Table 1.

\begin{tabular}{|c|c|c|c|c|c|c|}
\hline Narrow field & $\begin{array}{l}\text { Female } \\
\text { first }\end{array}$ & $\begin{array}{l}\text { Female } \\
\text { last }\end{array}$ & 2 auth & 3 auth & 4 auth & $5+$ auth \\
\hline Obstetrics and Gynecology & $0.027^{* * *}$ & $0.020 * *$ & $0.327 * * *$ & $0.425^{* * *}$ & $0.476 * * *$ & $0.611 * * *$ \\
\hline Reproductive Medicine & $-0.030 *$ & -0.009 & $0.223 * * *$ & $0.273^{* * *}$ & $0.273 * * *$ & $0.407 * * *$ \\
\hline Epidemiology & $0.016^{*}$ & -0.013 & $0.202 * * *$ & $0.271^{* * *}$ & $0.319 * * *$ & $0.392 * * *$ \\
\hline $\begin{array}{l}\text { Public Health, Environmental and } \\
\text { Occupational Health }\end{array}$ & $0.025^{* * *}$ & $-0.017 * * *$ & $0.334^{* * *}$ & $0.445^{* * *}$ & $0.501^{* * *}$ & $0.578 * * *$ \\
\hline $\begin{array}{l}\text { Pediatrics, Perinatology and Child } \\
\text { Health }\end{array}$ & $0.050^{* * *}$ & $0.022^{* * *}$ & $0.291 * * *$ & $0.400 * * *$ & $0.477^{* * *}$ & $0.622 * * *$ \\
\hline Geriatrics and Gerontology & 0.014 & -0.014 & $0.339 * * *$ & $0.446 * * *$ & $0.545^{* * *}$ & $0.665 * * *$ \\
\hline Embryology & 0.018 & 0.009 & $0.180 * * *$ & $0.194 * * *$ & $0.227^{* * *}$ & $0.250 * * *$ \\
\hline Psychiatry and Mental Health & $0.014^{* * *}$ & $-0.008^{*}$ & $0.364 * * *$ & $0.447^{* * *}$ & $0.504^{* * *}$ & $0.601 * * *$ \\
\hline Genetics (clinical) & $-0.057 * * *$ & $-0.057 * * *$ & $0.250 * * *$ & $0.259 * * *$ & $0.263^{* * *}$ & $0.371^{* * *}$ \\
\hline $\begin{array}{l}\text { Endocrinology, Diabetes and } \\
\text { Metabolism }\end{array}$ & 0.011 & -0.004 & $0.245 * * *$ & $0.364 * * *$ & $0.449 * * *$ & $0.576^{* * *}$ \\
\hline Rehabilitation & 0.012 & $-0.064 * * *$ & $0.344 * * *$ & $0.476 * * *$ & $0.564 * * *$ & $0.677 * * *$ \\
\hline Rheumatology & $0.027^{*}$ & 0.015 & $0.245 * * *$ & $0.310^{* * *}$ & $0.427 * * *$ & $0.567^{* * *}$ \\
\hline Dermatology & $-0.030 * *$ & -0.016 & $0.277^{* * *}$ & $0.295^{* * *}$ & $0.374 * * *$ & $0.543 * * *$ \\
\hline Health Policy & -0.006 & $-0.031 * * *$ & $0.389 * * *$ & $0.507^{* * *}$ & $0.581^{* * *}$ & $0.663 * * *$ \\
\hline Biochemistry (medical) & -0.002 & 0.007 & $0.215^{* * *}$ & $0.391 * * *$ & $0.527^{* * *}$ & $0.730 * * *$ \\
\hline $\begin{array}{l}\text { Complementary and Alternative } \\
\text { Medicine }\end{array}$ & $0.051^{* *}$ & 0.007 & $0.341^{* * *}$ & $0.534^{* * *}$ & $0.639 * * *$ & $0.764^{* * *}$ \\
\hline Infectious Diseases & $-0.011^{*}$ & $-0.013^{*}$ & $0.346^{* * *}$ & $0.397^{* * *}$ & $0.463^{* * *}$ & $0.568 * * *$ \\
\hline Health Informatics & 0.027 & $-0.061 * * *$ & $0.291^{* * *}$ & $0.286^{* * *}$ & $0.379 * * *$ & $0.481 * * *$ \\
\hline Drug Guides & -0.069 & -0.120 & $0.242 * *$ & 0.213 & $0.330^{*}$ & $0.334 * *$ \\
\hline Family Practice & 0.025 & 0.000 & $0.519 * * *$ & $0.634 * * *$ & $0.738 * * *$ & $0.972 * * *$ \\
\hline Pathology and Forensic Medicine & $-0.015^{*}$ & $-0.019 *$ & $0.112^{* * *}$ & $0.187^{* * *}$ & $0.185^{* * *}$ & $0.327^{* * *}$ \\
\hline Immunology and Allergy & -0.009 & $-0.020 * *$ & $0.195 * * *$ & $0.234^{* * *}$ & $0.316^{* * *}$ & $0.439 * * *$ \\
\hline Internal Medicine & -0.008 & -0.012 & $0.384 * * *$ & $0.543^{* * *}$ & $0.652 * * *$ & $0.770 * * *$ \\
\hline
\end{tabular}




\begin{tabular}{|c|c|c|c|c|c|c|}
\hline Oncology & -0.003 & $-0.014 * *$ & $0.383 * * *$ & $0.483^{* * *}$ & $0.546 * * *$ & $0.703 * * *$ \\
\hline Pharmacology (medical) & 0.008 & $-0.033 * * *$ & $0.341^{* * *}$ & $0.434 * * *$ & $0.499 * * *$ & $0.590 * * *$ \\
\hline Anatomy & 0.013 & -0.027 & $0.091^{* * *}$ & $0.116 * * *$ & $0.105^{* * *}$ & $0.286^{* * *}$ \\
\hline Hematology & 0.009 & $-0.023 * *$ & $0.297 * * *$ & $0.316^{* * *}$ & $0.357^{* * *}$ & $0.536^{* * *}$ \\
\hline Microbiology (medical) & $0.019^{*}$ & 0.011 & $0.384 * * *$ & $0.455^{* * *}$ & $0.569 * * *$ & $0.704^{* * *}$ \\
\hline Anesthesiology and Pain Medicine & $0.031^{* *}$ & $0.033^{* *}$ & $0.395^{* * *}$ & $0.516 * * *$ & $0.619 * * *$ & $0.804^{* * *}$ \\
\hline Histology & 0.002 & -0.015 & $0.097^{* *}$ & $0.167 * * *$ & $0.184^{* * *}$ & $0.296 * * *$ \\
\hline Transplantation & -0.009 & $-0.043 * * *$ & $0.129 * * *$ & $0.189 * * *$ & $0.309 * * *$ & $0.420 * * *$ \\
\hline Nephrology & -0.019 & $-0.080 * * *$ & $0.173^{* * *}$ & $0.247^{* * *}$ & $0.351^{* * *}$ & $0.523 * * *$ \\
\hline $\begin{array}{l}\text { Critical Care and Intensive Care } \\
\text { Medicine }\end{array}$ & 0.006 & -0.010 & $0.208^{* * *}$ & $0.319 * * *$ & $0.422 * * *$ & $0.631^{* * *}$ \\
\hline Emergency Medicine & $-0.027^{*}$ & $-0.029 *$ & $0.425^{* * *}$ & $0.640 * * *$ & $0.768^{* * *}$ & $0.966^{* * *}$ \\
\hline Ophthalmology & $-0.037 * * *$ & 0.000 & $0.340^{* * *}$ & $0.414^{* * *}$ & $0.531^{* * *}$ & $0.720 * * *$ \\
\hline Physiology (medical) & 0.008 & 0.003 & $0.082^{* * *}$ & $0.103^{* * *}$ & $0.131^{* * *}$ & $0.293^{* * *}$ \\
\hline Neurology (clinical) & $0.017 * * *$ & $0.014 * *$ & $0.261 * * *$ & $0.341 * * *$ & $0.415^{* * *}$ & $0.558^{* * *}$ \\
\hline Otorhinolaryngology & $0.050^{* * *}$ & $0.080 * * *$ & $0.156^{* * *}$ & $0.225^{* * *}$ & $0.339 * * *$ & $0.532 * * *$ \\
\hline Gastroenterology & $-0.036 * * *$ & $-0.037 * *$ & $0.240^{* * *}$ & $0.323 * * *$ & $0.473^{* * *}$ & $0.682^{* * *}$ \\
\hline Pulmonary and Respiratory Medicine & 0.009 & 0.011 & $0.211^{* * *}$ & $0.329 * * *$ & $0.401 * * *$ & $0.649 * * *$ \\
\hline Urology & $-0.051 * * *$ & -0.010 & $0.575^{* * *}$ & $0.696 * * *$ & $0.799 * * *$ & $0.965^{* * *}$ \\
\hline $\begin{array}{l}\text { Radiology, Nuclear Medicine and } \\
\text { Imaging }\end{array}$ & -0.005 & $-0.038 * * *$ & $0.257 * * *$ & $0.355^{* * *}$ & $0.492 * * *$ & $0.686 * * *$ \\
\hline Hepatology & -0.011 & -0.012 & $0.183^{* * *}$ & $0.217^{* * *}$ & $0.419 * * *$ & $0.579 * * *$ \\
\hline Surgery & 0.006 & $0.014^{*}$ & $0.257^{* * *}$ & $0.376^{* * *}$ & $0.479 * * *$ & $0.683^{* * *}$ \\
\hline $\begin{array}{l}\text { Cardiology and Cardiovascular } \\
\text { Medicine }\end{array}$ & $0.035^{* * *}$ & $0.043^{* * *}$ & $0.219 * * *$ & $0.310 * * *$ & $0.413^{* * *}$ & $0.669 * * *$ \\
\hline Orthopedics and Sports Medicine & -0.011 & -0.010 & $0.334^{* * *}$ & $0.457 * * *$ & $0.570 * * *$ & $0.708^{* * *}$ \\
\hline
\end{tabular}

\section{Discussion}

The female first and last authored journal article share increase in all 46 categories 1996-2018 confirms on a systematic level increases found in many previous studies of medical journals or specialisms. ${ }^{19,20,35,36,37,38}$ The lower rate of increase for female last authors similarly provides a systematic confirmation of previous studies with a more limited scope, ${ }^{20,35,37,38}$ although two studies had partly conflicting findings. ${ }^{18,40}$ It nevertheless remains possible that there are narrower specialisms in which the female participation rate has not increased.

Most medical fields still have male first author majorities, but this may naturally reduce as more male-dominated generations retire. More concerning is the much slower progress in female last authors, echoing continuing male domination of senior roles and much slower progress towards overturning this gender imbalance. Disparities of up to a factor of 7 between fields in female participation rates are also concerning for fields near the bottom of Table 1 . There is awareness from some of these fields of gender disparity issues, including surgery ${ }^{41,42,43}$ 
and Neurology ${ }^{44}$ (International Women in MS), but perhaps not of their position in relation to the rest of medicine. Causes of gender disparities in careers are complex, however, and may include socialised gender differences in career preferences, ${ }^{45,46}$ so explicit bias is not necessarily the cause of female under-representation in any field.

The female first author citation advantage in more fields than the opposite (whether considering statistically significant results or all results) is surprising, given that previous medical research has tended to find males to be more highly cited, and to have a higher h-index, or for there to be no gender differences if career and/or seniority factors are considered. The findings agree with one citations per-paper analysis of neurosurgery ${ }^{47}$ however.

The most important discrepancy is with a study of 1,269,542 journal articles and reviews 2008-14 from the MeSH Diseases category of PubMed Medline, matched with the Web of Science for citations. Using field-normalised citation counts (not log-transformed in the denominator but using a much finer-grained and probably more accurate set of fields), male first-authored articles had a 3.4\% higher median than that for female first-authored articles $(0$. 759 vs. 0.734$){ }^{23}$ The discrepancy could be due to the different fields covered in the prior paper, the inclusion of review articles (which tend to be highly cited and can therefore be influential), the inclusion of international collaborative articles (international collaboration favours males), ${ }^{23}$ the shorter time span, the inclusion of multiple countries, or not taking into account collaboration (in the first analysis of the prior paper). ${ }^{23}$ Multiple countries could cause the discrepancy if women are first author more often in countries with fewer resources, although this did not seem to be the case. ${ }^{23}$ The most likely two causes seem to be the inclusion of internationally collaborative research and not considering the help provided by collaboration. The prior research also reported a regression analysis, different to the one here, for example considering journal impact factors and collaboration (in a different way to above). The female citation advantage shrank, but did not disappear, with this regression. A plausible cause of the continued discrepancy (slight male advantage vs. slight female advantage in the current paper) is the inclusion of internationally collaborative research (a male citation advantage), although field and country coverage differences could also be explanations.

There are many reasons why one gender may tend to be cited more in a field, other than that their research tends to be more impactful. Men tend to self-cite more than women, ${ }^{48}$ although self-citation may not be prevalent in all medical fields, ${ }^{49}$ and so the underlying impact of female first-authored research may be underestimated in some areas. Articles are more likely to be cited if they are from some narrow specialisms, ${ }^{50}$ so it is possible that citation advantages are due to the over-representation of one gender within these specialisms.

The tendency for a male last author citation advantage is a new type of finding. Since last authors tend to be senior, this implies that male last authors tend to oversee research with slightly more citation impact. There are different plausible explanations for this, other than gender differences in team leadership skills. Senior males may tend to be more successful with funding bids, therefore overseeing better financed research. Alternatively, team research with a female last author may tend to be of a different type: it may be less likely to be laboratory or departmental research with a senior last author. If true, then the research may be less well financed.

Female first authors and male last authors tend to work in larger teams in most fields. Again, there are multiple possible explanations. For first authors, females may tend to work on more complex projects requiring more input or may be less likely to author solo articles, such as theoretical or invited opinion pieces. For last authors, males may be more likely to be the senior of a team than a participant that happens to be in last place. Males may also tend to lead more complex projects or larger departments, with occasionally large teams. The gender differences in citation rates are strengthened if team size is ignored in the analysis. 
Given that previous research factoring out seniority and/or career factors when comparing career citations, has not found statistically significant evidence of gender differences in productivity, career citations or the h-index, $, 7,15,16,17$ the tendencies for small female first author and male last author citation advantages found here are the only known publishing-based gender differences in medicine that cannot be accounted for by career factors. These occur irrespective of team size. Since last authors tend to be senior, females applying for medical posts should therefore tend to have a small $\mathrm{CV}$ advantage if citations are considered for publications where they were the main (first) author. In contrast, males may have an advantage in situations where senior researchers are being compared, such as prestigious senior positions, career achievement awards or honorary senior positions. Nevertheless, the key takeaway message is that medical research tends to have slightly higher citation impact when females are its main contributors. Thus, in any situation where males appear to be outperforming females on citation-based indicators, care should be taken to examine whether this is due to ignoring career factors, thereby biasing the results in favour of males.

\section{References}

1. Thomas BR and Dockter N. Affirmative action and holistic review in medical school admissions: Where we have been and where we are going. Acad Med 2019; 94(4): 473-476.

2. Athanasiou T, Patel V, Garas G, Ashrafian H, Hull L, Sevdalis N, Harding S, Darzi $\mathrm{A}$, and Paroutis S. Mentoring perception, scientific collaboration and research performance: is there a 'gender gap' in academic medicine? An Academic Health Science Centre perspective. Postgrad Med J 2016; 92(1092): 581-586.

3. Henderson MT, Fijalkowski N, Wang SK, Maltenfort M, Zheng LL, Ratliff J, Moshfeghi AA, and Moshfeghi DM. Gender differences in compensation in academic medicine: The results from four neurological specialties within the University of California Healthcare System. Scientometrics. 2014; 100(1): 297-306.

4. Thibault GE. Women in academic medicine. Acad Med 2016; 91(8): 1045-1046.

5. Diamond SJ, Thomas CR, Desai S, Holliday EB, Jagsi R, Schmitt C, and Enestvedt BK. Gender differences in publication productivity, academic rank, and career duration among US academic gastroenterology faculty. Acad Med 2016 Aug 1; 91(8): 1158-1163.

6. Carr PL, Raj A, Kaplan SE, Terrin N, Breeze JL, and Freund KM. Gender differences in academic medicine: retention, rank, and leadership comparisons from the National Faculty Survey. Acad Med 2018; 93(11): 1694-1699.

7. Yang HY, Rhee G, Xuan L, Silver JK, Jalal S, and Khosa F. Analysis of H-index in Assessing Gender Differences in Academic Rank and Leadership in Physical Medicine and Rehabilitation in the United States and Canada. Am J Phys Med Rehab 2019; 98(6): 479-483.

8. Schor NF. The decanal divide: Women in decanal roles at US medical schools. Acad Med 2018; 93(2): 237-240.

9. Bank AM, Slocum CS, Blauwet CA, Bhatnagar S, Poorman JA, Goldstein R, Reilly JM, Zafonte RD, and Silver JK. Author response: Women physicians underrepresented in American Academy of Neurology recognition awards. Neurology 2019; 92(19): 924.

10. King Jr JT, Angoff NR, Forrest Jr JN, and Justice AC. Gender disparities in medical student research awards: a 13-year study from the Yale School of Medicine. Acad Med 2018; 93(6): 911-919. 
11. Raj A, Carr PL, Kaplan SE, Terrin N, Breeze JL, and Freund KM. Longitudinal analysis of gender differences in academic productivity among medical faculty across 24 medical schools in the United States. Acad Med 2016; 91(8): 1074.

12. Gunashekar, S., Wooding, S., and Guthrie, S. How do NIHR peer review panels use bibliometric information to support their decisions? Scientometrics 2017; 112(3), 1813-1835.

13. Bendels MH, Dietz MC, Brüggmann D, Oremek GM, Schöffel N, and Groneberg DA. Gender disparities in high-quality dermatology research: a descriptive bibliometric study on scientific authorships. BMJ Open 2018; 8(4): e020089.

14. Sing DC, Jain D, and Ouyang D. Gender trends in authorship of spine-related academic literature-a 39-year perspective. Spine J 2017; 17(11): 1749-1754.

15. Geltzeiler CB, Kelley KA, and Srikanth P, Does sex influence publication productivity among colorectal surgeons participating in fellowship training programs? Dis Colon Rectum 2017; 60: 537-543.

16. Myers, S. P., Reitz, K. M., Wessel, C. B., Neal, M. D., Corbelli, J. A., Hausmann, L. R., and Rosengart MR. A systematic review of gender-based differences in Hirsch index among academic surgeons. J Surg Res 2019; 236, 22-29.

17. Mueller CM, Gaudilliere DK, and Kin C, Gender disparities in scholarly productivity of US academic surgeons. J Surg Res 2016; 203: 28-33.

18. McKenzie K, Ramonas M, Patlas M, and Katz DS. Assessing the gap in female authorship in the journal Emergency Radiology: trends over a 20 -year period. Emerg $\operatorname{Rad} 2017$; 24(6): 641-644.

19. Wininger AE, Fischer JP, Likine EF, Gudeman AS, Brinker AR, Ryu J, Maupin KA, Lunsford S, Whipple EC, Loder RT, and Kacena MA. Bibliometric Analysis of Female Authorship Trends and Collaboration Dynamics Over JBMR's 30-Year History. J Bone Mineral Res 2017; 32(12): 2405-2414.

20. Fishman M, Williams II WA, Goodman DM, and Ross LF. Gender differences in the authorship of original research in pediatric journals, 2001-2016. J Pediatrics 2017; 191: 244-249.

21. Lewison G, Roe P, Webber R, and Sullivan R. Lung cancer researchers, 2008-2013: their sex and ethnicity. Scientometrics 2016; 106(1): 105-117.

22. Larivière V, Ni C, Gingras Y, Cronin B, and Sugimoto CR. Bibliometrics: Global gender disparities in science. Nature News2013; 504: 211-213.

23. Andersen JP, Schneider JW, Jagsi R, Nielsen MW. Gender variations in citation distributions in medicine are very small and due to self-citation and journal prestige. Elife. 2019;8.

24. Mongeon P and Paul-Hus A. The journal coverage of Web of Science and Scopus: a comparative analysis. Scientometrics 2016; 106: 213-228.

25. Abramo G, Cicero T, and D'Angelo CA. Assessing the varying level of impact measurement accuracy as a function of the citation window length. J Informetrics 2011; 5: 659-667.

26. Thelwall M, Bailey C, Tobin C, and Bradshaw N. Gender differences in research areas, methods and topics: Can people and thing orientations explain the results? J Informetrics 2019; 13: 149-169.

27. Zhang L, Rousseau R, Glänzel W. Diversity of references as an indicator of the interdisciplinarity of journals: Taking similarity between subject fields into account. Journal of the Association for Information Science and Technology. 2016 May;67(5):1257-65.

28. Thelwall M. Are the discretised lognormal and hooked power law distributions plausible for citation data? J Informetrics 2016; 10(2): 454-470. 
29. Limpert E, Stahel WA, and Abbt M. Log-normal distributions across the sciences: keys and clues: on the charms of statistics, and how mechanical models resembling gambling machines offer a link to a handy way to characterize log-normal distributions, which can provide deeper insight into variability and probability normal or log-normal: that is the question. BioScience. 2001; 51(5): 341-352.

30. Thelwall M. Three practical field normalised alternative indicator formulae for research evaluation. J Informetrics 2017; 11: 128-151.

31. Larivière V, Desrochers N, and Macaluso B, Contributorship and division of labor in knowledge production. Soc Stud Sci 2016; 46: 417-435.

32. Larivière V, Gingras Y, Sugimoto CR, and Tsou A. Team size matters: Collaboration and scientific impact since 1900. J Assoc Inf Sci Technol 2015; 66: 1323-1332.

33. Rousseeuw, P., Croux, C., Todorov, V., Ruckstuhl, A., Salibian-Barrera, M., Verbeke, T., and Maechler, M. (2019). robustbase: Basic Robust Statistics. R package version 0.92-8.

34. Yohai VJ. High breakdown-point and high efficiency robust estimates for regression. Ann Stat 1987; 15: 642-656.

35. Russell AF, Lode, RT, Gudeman AS, Bolaji P, Virtanen P, Whipple EC, and Kacena MA. A bibliometric study of authorship and collaboration trends over the past 30 years in four major musculoskeletal science journals. Calc Tiss Internat 2019: 104: 239-250.

36. Metheny WP, Jagadish M, andHeidel RE. A 15-year study of trends in authorship by gender in two US obstetrics and gynecology journals. Obs Gyn 2018; 131(4): 696699.

37. Khan F, Sandelski MM, Rytlewski JD, Lamb J, Pedro C, Adjei MB, Lunsford S, Fischer JP, Wininger AE, Whipple EC, and Loder RT. Bibliometric analysis of authorship trends and collaboration dynamics over the past three decades of BONE's publication history. Bone 2018; 107: 27-35.

38. Gayet-Ageron A, Poncet A, and Perneger T. Comparison of the contributions of female and male authors to medical research in 2000 and 2015: a cross-sectional study. BMJ Open 2019; 9(2): e024436.

39. Sheridan G, Wisken E, Hing CB, and Smith TO. A bibliometric analysis assessing temporal changes in publication and authorship characteristics in The Knee from 1996 to 2016. The Knee 2018; 25(2): 213-238.

40. Bendels MH, Bauer J, Schöffel N, and Groneberg DA. The gender gap in schizophrenia research. Schiz Res 2018; 193: 445-446.

41. Antonoff MB, David EA, Donington JS, et al. Women in thoracic surgery: 30 years of history. Ann Thorac Surg. 2016; 101: 399-409.

42. Bucknor A, Kamali P, Phillips N, et al. Gender inequality for women in plastic surgery: A systematic scoping review. Plast Reconstr Surg. 2018; 141: 1561-1577.

43. Seemann NM, Webster F, Holden HA, et al. Women in academic surgery: why is the playing field still not level? Am J Surg 2016; 211: 343-349.

44. International Women in MS. Gender Inequities in the multiple sclerosis community: a call for action. Ann Neurology 2018 Dec; 84(6): 958-959.

45. Diekman AB, Steinberg M, Brown ER, Belanger AL, and Clark EK. A goal congruity model of role entry, engagement, and exit: Understanding communal goal processes in STEM gender gaps. Pers Soc Psych Rev 2017; 21: 142-175.

46. Su R, Rounds J, and Armstrong PI. Men and things, women and people: a metaanalysis of sex differences in interests. Psych Bull. 2009; 135: 859-871. 
47. Sotudeh H, Dehdarirad T, and Freer J. Gender differences in scientific productivity and visibility in core neurosurgery journals: Citations and social media metrics. Res Eval. 2018; 27: 262-269.

48. King MM, Bergstrom CT, Correll SJ, et al. Men set their own cites high: Gender and self-citation across fields and over time. Socius, 2017; 3: 2378023117738903.

49. Yheulon CG, Balla FM, Patel AD, et al. Publication patterns and the impact of selfcitation among minimally invasive surgery fellowships. Am J Surg 2019; 217: 346349.

50. Cheng KL, Dodson TB, Egbert MA, and Susarla SM. Which factors affect citation rates in the oral and maxillofacial surgery literature? J Oral Maxillofac Surg 2017; 75: 1313-1318.

\section{Appendix}

Table A1. Average team sizes 2018 for 46 Scopus narrow Medicine fields (US only) by first and last author gender (order as for Table 1).

\begin{tabular}{|c|c|c|c|c|c|}
\hline Narrow field & Articles & $\begin{array}{l}\text { Female first } \\
\text { team size }\end{array}$ & $\begin{array}{l}\text { Male first } \\
\text { team size }\end{array}$ & $\begin{array}{l}\text { Female last } \\
\text { team size }\end{array}$ & $\begin{array}{l}\text { Male last } \\
\text { team size }\end{array}$ \\
\hline Obstetrics and Gynecology & 1885 & 4.47 & 4.17 & 4.30 & 4.48 \\
\hline Reproductive Medicine & 450 & $4.98^{*}$ & 4.25 & 4.57 & 4.87 \\
\hline Epidemiology & 1530 & $5.37^{* * *}$ & 4.56 & 5.17 & 4.93 \\
\hline $\begin{array}{l}\text { Public Health, Environmental and } \\
\text { Occupational Health }\end{array}$ & 6159 & $4.21 * * *$ & 3.77 & 3.99 & 4.06 \\
\hline $\begin{array}{l}\text { Pediatrics, Perinatology and Child } \\
\text { Health }\end{array}$ & 4849 & 4.32 & 4.38 & 4.10 & $4.56^{* * *}$ \\
\hline Geriatrics and Gerontology & 1033 & 4.53 & 4.65 & 4.29 & $4.87 * *$ \\
\hline Embryology & 105 & 4.78 & 4.36 & 4.41 & 4.80 \\
\hline Psychiatry and Mental Health & 5827 & $4.16 * * *$ & 3.79 & 3.93 & $4.07 * * *$ \\
\hline Genetics (clinical) & 1032 & $5.68^{*}$ & 5.18 & 5.55 & 5.40 \\
\hline $\begin{array}{l}\text { Endocrinology, Diabetes and } \\
\text { Metabolism }\end{array}$ & 1385 & 5.68 & 5.34 & 5.44 & 5.59 \\
\hline Rehabilitation & 1076 & 3.83 & 4.04 & 3.58 & $4.21 * * *$ \\
\hline Rheumatology & 291 & 5.37 & 5.25 & 5.21 & 5.40 \\
\hline Dermatology & 1269 & 3.89 & 3.71 & 3.79 & 3.81 \\
\hline Health Policy & 2716 & $3.75^{* * *}$ & 3.06 & 3.48 & 3.35 \\
\hline Biochemistry (medical) & 205 & 5.80 & 4.74 & 5.08 & 5.37 \\
\hline $\begin{array}{l}\text { Complementary and Alternative } \\
\text { Medicine }\end{array}$ & 307 & 2.97 & 2.54 & 2.84 & 2.68 \\
\hline Infectious Diseases & 2489 & $5.47^{* * *}$ & 4.83 & 5.25 & 5.08 \\
\hline Health Informatics & 871 & 4.60 & 4.74 & 4.28 & $4.97^{* *}$ \\
\hline Drug Guides & 2 & 2.00 & 2.00 & 2.00 & 2.00 \\
\hline Family Practice & 346 & $3.23 * *$ & 2.62 & 2.87 & 2.93 \\
\hline Pathology and Forensic Medicine & 1535 & 3.70 & 3.61 & 3.50 & 3.75 \\
\hline Immunology and Allergy & 1789 & 5.80 & 5.71 & 5.77 & 5.74 \\
\hline
\end{tabular}




\begin{tabular}{|c|c|c|c|c|c|}
\hline Internal Medicine & 948 & 5.21 & 4.92 & 4.67 & $5.31 * *$ \\
\hline Oncology & 4517 & 6.45 & $6.64^{*}$ & 6.01 & $6.87 * * *$ \\
\hline Pharmacology (medical) & 1981 & 4.71 & 4.42 & 4.48 & 4.59 \\
\hline Anatomy & 379 & 3.74 & 3.39 & 3.40 & 3.64 \\
\hline Hematology & 1229 & 5.63 & 5.78 & 5.15 & $5.97^{* *}$ \\
\hline Microbiology (medical) & 1072 & $5.39 * * *$ & 4.66 & 5.11 & 4.93 \\
\hline Anesthesiology and Pain Medicine & 999 & $4.76^{*}$ & 4.17 & $4.76^{*}$ & 4.27 \\
\hline Histology & 450 & 4.38 & 4.05 & 4.15 & 4.21 \\
\hline Transplantation & 614 & 6.80 & 6.65 & 6.58 & 6.77 \\
\hline Nephrology & 458 & 5.41 & 4.95 & 4.84 & 5.24 \\
\hline $\begin{array}{l}\text { Critical Care and Intensive Care } \\
\text { Medicine }\end{array}$ & 881 & 4.56 & 4.42 & 4.41 & 4.51 \\
\hline Emergency Medicine & 1369 & 3.86 & 4.06 & 3.60 & $4.18 * * *$ \\
\hline Ophthalmology & 1255 & 4.37 & 4.03 & 4.32 & 4.09 \\
\hline Physiology (medical) & 1401 & 4.89 & 5.05 & 4.86 & 5.04 \\
\hline Neurology (clinical) & 4910 & 5.24 & 5.19 & 5.14 & 5.24 \\
\hline Otorhinolaryngology & 1438 & 4.20 & 4.08 & 3.95 & $4.19 *$ \\
\hline Gastroenterology & 1274 & 4.68 & 4.63 & 4.32 & 4.74 \\
\hline Pulmonary and Respiratory Medicine & 1629 & 5.47 & 5.47 & 5.61 & 5.42 \\
\hline Urology & 1335 & 5.20 & $5.56^{* * *}$ & 5.31 & 5.47 \\
\hline $\begin{array}{l}\text { Radiology, Nuclear Medicine and } \\
\text { Imaging }\end{array}$ & 3487 & 4.86 & 4.91 & 4.63 & 4.97 \\
\hline Hepatology & 493 & 5.19 & 5.32 & 4.47 & $5.51^{*}$ \\
\hline Surgery & 7256 & 4.99 & 4.85 & 4.97 & 4.87 \\
\hline $\begin{array}{l}\text { Cardiology and Cardiovascular } \\
\text { Medicine }\end{array}$ & 3898 & 5.57 & 5.58 & 5.61 & 5.56 \\
\hline Orthopedics and Sports Medicine & 3863 & 4.33 & $4.52^{*}$ & 4.02 & $4.57^{* * *}$ \\
\hline
\end{tabular}


Table A2. Regression coefficients for three reduced regression models for each of 46 Scopus narrow Medicine fields (US only, first and last author gendered), ignoring team size.

Publication year regression coefficients are not shown. Order as for Table 1.

\begin{tabular}{|c|c|c|c|c|}
\hline & \multicolumn{2}{|c|}{ Model 2} & \multirow{2}{*}{$\begin{array}{l}\text { Model } 3 \\
\text { Female } \\
\text { 1st }\end{array}$} & \multirow{2}{*}{$\begin{array}{l}\text { Model } 4 \\
\text { Female } \\
\text { last }\end{array}$} \\
\hline Narrow field & $\begin{array}{l}\text { Female } \\
\text { 1st }\end{array}$ & $\begin{array}{l}\text { Female } \\
\text { last }\end{array}$ & & \\
\hline Obstetrics and Gynecology & $0.054 * * *$ & -0.002 & $0.054 * * *$ & 0.011 \\
\hline Reproductive Medicine & -0.006 & -0.022 & -0.010 & -0.023 \\
\hline Epidemiology & $0.050 * * *$ & -0.011 & $0.048 * * *$ & -0.001 \\
\hline Public Health, Environmental and Occupational Health & $0.057 * * *$ & $-0.034 * * *$ & $0.048 * * *$ & $-0.019 * * *$ \\
\hline Pediatrics, Perinatology and Child Health & $0.071^{* * *}$ & -0.006 & $0.069 * * *$ & $0.011^{*}$ \\
\hline Geriatrics and Gerontology & $0.020^{*}$ & $-0.073 * * *$ & 0.003 & $-0.068 * * *$ \\
\hline Embryology & 0.028 & 0.005 & 0.029 & 0.009 \\
\hline Psychiatry and Mental Health & $0.035^{* * *}$ & $-0.024 * * *$ & $0.031 * * *$ & $-0.017 * * *$ \\
\hline Genetics (clinical) & $-0.038 * * *$ & $-0.058 * * *$ & $-0.049 * * *$ & $-0.066 * * *$ \\
\hline Endocrinology, Diabetes and Metabolism & $0.039 * * *$ & $-0.022 * *$ & $0.036 * * *$ & $-0.014 *$ \\
\hline Rehabilitation & 0.008 & $-0.121 * * *$ & $-0.027 * *$ & $-0.118 * * *$ \\
\hline Rheumatology & $0.070 * * *$ & 0.028 & $0.074 * * *$ & $0.039 * *$ \\
\hline Dermatology & 0.010 & $-0.021^{*}$ & 0.007 & -0.019 \\
\hline Health Policy & $0.060 * * *$ & $-0.044 * * *$ & $0.044 * * *$ & $-0.021 *$ \\
\hline Biochemistry (medical) & $0.062 * * *$ & 0.018 & $0.064 * * *$ & 0.028 \\
\hline Complementary and Alternative Medicine & $0.074 * *$ & $-0.070 * *$ & $0.043^{*}$ & -0.037 \\
\hline Infectious Diseases & $0.011^{*}$ & $-0.016 * *$ & 0.009 & $-0.014 *$ \\
\hline Health Informatics & 0.018 & $-0.110 * * *$ & -0.023 & $-0.103 * * *$ \\
\hline Drug Guides & -0.060 & -0.083 & -0.095 & -0.109 \\
\hline Family Practice & $0.082 * *$ & -0.005 & $0.081^{* *}$ & 0.019 \\
\hline Pathology and Forensic Medicine & 0.003 & $-0.031 * * *$ & -0.002 & $-0.031 * * *$ \\
\hline Immunology and Allergy & $0.012^{*}$ & $-0.023 * * *$ & 0.009 & $-0.021 * *$ \\
\hline Internal Medicine & $0.043 * * *$ & $-0.034 * *$ & $0.039 * * *$ & $-0.026^{*}$ \\
\hline Oncology & $0.015^{* * *}$ & $-0.036 * * *$ & $0.009 *$ & $-0.033 * * *$ \\
\hline Pharmacology (medical) & $0.024^{* * *}$ & $-0.055^{* * *}$ & $0.016^{*}$ & $-0.051 * * *$ \\
\hline Anatomy & 0.015 & $-0.043 * *$ & 0.007 & $-0.040 * *$ \\
\hline Hematology & $0.041 * * *$ & $-0.029 * *$ & $0.037 * * *$ & $-0.023^{*}$ \\
\hline Microbiology (medical) & $0.068 * * *$ & 0.018 & $0.070 * * *$ & $0.027 * *$ \\
\hline Anesthesiology and Pain Medicine & $0.078 * * *$ & $0.036 * *$ & $0.085^{* * *}$ & $0.054^{* * *}$ \\
\hline
\end{tabular}




\begin{tabular}{|c|c|c|c|c|}
\hline Histology & 0.009 & -0.021 & 0.007 & -0.020 \\
\hline Transplantation & -0.009 & $-0.065 * * *$ & -0.017 & $-0.067 * * *$ \\
\hline Nephrology & 0.002 & $-0.107 * * *$ & -0.017 & $-0.106 * * *$ \\
\hline Critical Care and Intensive Care Medicine & 0.002 & $-0.075 * * *$ & -0.012 & $-0.075 * * *$ \\
\hline Emergency Medicine & -0.011 & $-0.076 * * *$ & $-0.026 *$ & $-0.078 * * *$ \\
\hline Ophthalmology & -0.006 & -0.004 & -0.007 & -0.005 \\
\hline Physiology (medical) & 0.011 & -0.010 & 0.010 & -0.008 \\
\hline Neurology (clinical) & $0.031 * * *$ & -0.009 & $0.029 * * *$ & -0.002 \\
\hline Otorhinolaryngology & $0.063^{* * *}$ & $0.076^{* * *}$ & $0.080 * * *$ & $0.092 * * *$ \\
\hline Gastroenterology & -0.015 & $-0.099 * * *$ & $-0.033 * *$ & $-0.102 * * *$ \\
\hline Pulmonary and Respiratory Medicine & $0.028 * * *$ & -0.009 & $0.027 * *$ & -0.002 \\
\hline Urology & -0.018 & $-0.031 *$ & $-0.023 *$ & $-0.036 * *$ \\
\hline Radiology, Nuclear Medicine and Imaging & $0.018 * *$ & $-0.067 * * *$ & 0.008 & $-0.064 * * *$ \\
\hline Hepatology & 0.023 & -0.013 & 0.021 & -0.010 \\
\hline Surgery & $0.030 * * *$ & -0.005 & $0.030 * * *$ & 0.001 \\
\hline Cardiology and Cardiovascular Medicine & $0.060 * * *$ & $0.016 *$ & $0.062 * * *$ & $0.028 * * *$ \\
\hline Orthopedics and Sports Medicine & -0.009 & $-0.036 * * *$ & $-0.016^{*}$ & $-0.038 * * *$ \\
\hline
\end{tabular}

